\title{
Thermodynamic stability and transformation of pharmaceutical polymorphs*
}

\author{
Mitsutaka Kitamura $\ddagger$ \\ Department of Mechanical and System Engineering, University of Hyogo, \\ 2167 Shosha, Himeji 671-2201, Japan
}

\begin{abstract}
The thermodynamic stability and transformation of pharmaceutical polymorphs was investigated, especially those of the thiazole derivative pharmaceutical, 2-(3-cyano-4isobutyloxyphenyl)-4-methyl-5-thiazolecarboxylic acid (BPT). The influence of methanol compositions in solvents and temperature on the solubility and the transformation behavior of BPT was clarified. The transformation behavior was explained by the chemical potential difference between the stable and metastable forms. It was shown that a specific solute-solvent interaction contributes to the preferential nucleation and growth of the stable or metastable forms and influences the transformation behaviors. The solubility of BPT of the solvated crystals is much more influenced by the solvent compositions than the true polymorphs. The solubility ratio of the solvated crystals depends on the solvent composition, whereas the solubility ratio of the true polymorphs is considered to be independent of the solvents. The crystallization behavior was also investigated. The transformation rate after crystallization appeared to depend on the initial concentration of BPT and the addition rate of the antisolvent. The cause of this phenomenon was presumed to be a slight inclusion of the stable form in the metastable form.
\end{abstract}

Keywords: polymorphs; solubility; transformation; thermodynamic stability; crystallization; nucleation; pharmaceutical.

\section{INTRODUCTION}

In the pharmaceutical industry, polymorphs and solvated crystals, called pseudo-polymorphs, appear frequently. Control of the crystallization behavior of these polymorphous crystals is important, because physical properties such as the solubility, the melting point, and the solid density are different among these polymorphs [1]. Owing to the differences of solubility and dissolution rates between polymorphs, the bioavailability of pharmaceuticals depends on polymorphous crystals [2-4]. The crystallization process of polymorphs is composed of elementary processes of competitive nucleation, growth, and transformation from a metastable to a stable form. For selective crystallization of polymorphs, the mechanism of these elementary processes needs to be clear in relation to the operational conditions and the key controlling factors [1]. Solubility is an important factor because the relative thermodynamic stability of polymorphs and the direction of the transformation between them are determined by the solubility of polymorphs. Furthermore, the supersaturation of each polymorph, which is different even in the same solutions, is also based on the solubility of each polymorph. The transformation from a

\footnotetext{
*Paper based on a presentation at the $11^{\text {th }}$ International Symposium on Solubility Phenomena ( $11^{\text {th }}$ ISSP), Aveiro, Portugal, 25-29 July 2004. Other presentations are published in this issue, pp. 513-665.

¥Tel: 0792-67-4850; E-mail: mkitamura@eng.u-hyogo.ac.jp
} 
metastable to a stable form frequently occurs during crystallization, and possibly even after the completion of crystallization. This fact makes the crystallization process complicated. We have observed that transformation behavior is influenced by temperature [5,6], additives [7-8], and solvents [9-11]. In the pharmaceutical industry, antisolvents are frequently used for crystallizations. In this process, the solvent compositions change with time, and crystallization and transformation behaviors of the polymorphs could be strongly influenced by the change of solvent composition. For example, the relative nucleation and growth rates of the polymorphs (A, B) of L-histidine and the transformation rate from the metastable B to the stable A form depend on the solvent composition in a mixture of water and ethanol [9]. Therefore, the dependence of the transformation and crystallization behaviors of polymorphous crystals on temperature and solvent composition should be understood to help with the control of polymorphism. However, these quantitative relationships have not been made clear.

In this study, we dealt with a thiazole derivative pharmaceutical, 2-(3-cyano-4-isobutyloxyphenyl)-4-methyl-5-thiazolecarboxylic acid (BPT), which is an enzyme inhibitor and has various polymorphs and solvated crystals. The influence of both the solvent composition in the methanol-water mixture and the temperature on the thermodynamic stability and transformation behavior of these polymorphous crystals was investigated. Crystallization behavior was also examined by the addition of water as an antisolvent to the methanol solutions.

\section{EXPERIMENTAL}

BPT has three polymorphs (A, B, C) and two solvated crystals-hydrated crystal, $\mathrm{BH}\left(\mathrm{BPT} \cdot \mathrm{H}_{2} \mathrm{O}\right)$ and methanolated crystal, D (BPT $\cdot \mathrm{MeOH})$ [12]. In atmosphere, the BH crystal loses very slowly the solvated water molecules and becomes an anhydrous crystal (B). Excess amounts of A, BH, C, and D crystals were added to the methanol and water solutions in a glass vessel $(50 \mathrm{ml})$ in a thermostatic bath while stirring with a magnetic stirrer. The methanol volume fraction $\left(V_{\mathrm{MeOH}}\right)$ in the solution was changed from 0.5 to 0.9 . The suspension was filtrated, and the solution's change of concentration over time was measured by a UV spectroscopic method, using adsorption at $317 \mathrm{~nm}$. The filtrated crystals were dried in atmosphere, and the transformation behavior was examined by analyzing the polymorphous composition of the crystals by X-ray diffraction (XRD), using the characteristic peak [12]. Solubility measurements were carried out in a temperature range between 303 and $323 \mathrm{~K}$.

For crystallization, a 50-ml glass cylindrical crystallizer, with a jacket to circulate the thermostatted water, was used. The BPT $(0.5-1 \mathrm{~g})$ was dissolved at $323 \mathrm{~K}$ in $40 \mathrm{ml}$ of the methanol and water mixture with a methanol volume fraction $\left(V_{\mathrm{MeOH}}\right)$ of 0.95 . Crystallization was carried out by pumping $14 \mathrm{ml}$ of water as an antisolvent into the methanol solution at $323 \mathrm{~K}$ while stirring with an impeller. Then, the final methanol composition $\left(V_{\mathrm{MeOH}}\right)$ of the solution was 0.7 . The rate of water addition $(W)$ as an operational condition was changed from 0.2 to $2.0 \mathrm{ml} / \mathrm{min}$. At the end of water addition, the slurry was sampled and quickly filtrated. The polymorphous composition of the dried crystals was analyzed by XRD.

\section{RESULTS AND DISCUSSION}

\section{Thermodynamic stability of polymorphs}

The equilibrium conditions between the solid and liquid phases can be expressed by eq. 1 using the chemical potential of the solute.

The solubility of a solid (i), in solutions is usually expressed by eq. 1 [13].

$$
\ln a_{i}=-\frac{\Delta H_{i \mathrm{~m}}}{R T}\left(1-\frac{T}{T_{i \mathrm{~m}}}\right)+\frac{\Delta C_{i \mathrm{p}}}{R}\left(\frac{T_{i \mathrm{~m}}}{T}-1\right)-\frac{\Delta C_{i p}}{R} \ln T_{i \mathrm{~m}} / T
$$


where $\alpha_{i}$ is activity and $T_{i \mathrm{~m}}$ is the melting point of pure $i$ component; $\Delta H_{i \mathrm{~m}}$ is enthalpy of fusion at $T_{i \mathrm{~m}}$; $\Delta C_{\mathrm{p}}$ is the difference of molar heat capacity between liquid and solid.

Equation 1 is usually simplified as eq. 2,

$$
\ln a_{i}=\frac{\Delta H_{i \mathrm{~m}}}{R}\left(\frac{1}{T_{i \mathrm{~m}}}-\frac{1}{T}\right)
$$

The activity is shown as

$$
a_{i}=\gamma_{i} \cdot X_{i}
$$

where $\gamma_{i}$ is activity coefficient and $X_{i}$ is solubility in mole fraction.

The solubility ratio of the polymorphs of the A and B forms, for example, can be expressed as

$$
\frac{\partial \ln \left(a_{\mathrm{A}} / a_{\mathrm{B}}\right)}{\partial(1 / T)}=\frac{1}{R}\left(\Delta H_{\mathrm{Bm}}-\Delta H_{\mathrm{Am}}\right)=\frac{-\Delta H_{\mathrm{tr}}}{R}
$$

where $\Delta H_{\mathrm{tr}}$ is the enthalpy for the transformation between the $\mathrm{A}$ and $\mathrm{B}$ forms.

It is assumed that the activity coefficients $\left(\gamma_{i}\right)$ of each polymorph in the same solution may be regarded as equal, since the molecular structure of the polymorphs is the same. Accordingly, the activity ratio can be substituted by the solubility $\left(X_{i}\right)$ ratio,

$$
\frac{\partial \ln \left(a_{\mathrm{A}} / a_{\mathrm{B}}\right)}{\partial(1 / T)} \approx \frac{\partial \ln \left(x_{\mathrm{A}} / x_{\mathrm{B}}\right)}{\partial(1 / T)}
$$

This equation suggests that the solubility ratio and the transition point do not depend on solvent type.

The chemical potential difference between the metastable (A) and stable (B) forms is written as eq. 6

$$
\Delta \mu(\mathrm{s})=R T \ln \frac{x_{\mathrm{A}}}{x_{\mathrm{B}}}
$$

For example, it was observed previously $[5,6]$ that the polymorphs of L-glutamic acid (L-Glu) ( $\alpha$ and $\beta$ ) and L-histidine (L-His) (A, B) show monotropic solubility curves. However, the solubility ratio of the metastable form of $\alpha$ to the stable form of $\beta$ in the case of L-Glu (1.25-1.48) [5] is larger than that of the metastable form of B to the stable form of A for L-His (1.04-1.08) [6]. In the case of L-His, the conformational difference between the $\mathrm{A}$ and $\mathrm{B}$ polymorphs is very small in comparison with that of L-Glu polymorphs ( $\alpha$ and $\beta$ ). This corresponds to the small difference of the chemical potential between the polymorphs in the case of L-His.

\section{Solubility and transformation behaviors of thiazole derivative}

\section{Effect of solvent composition on solubility and transformation of polymorphs at $323 \mathrm{~K}$}

Figure 1 shows the typical concentration change of BPT after the excess crystals was added to the solution at a methanol volume fraction $\left(V_{\mathrm{MeOH}}\right)$ of 0.7 .

When $\mathrm{A}$ and $\mathrm{C}$ crystals were added to the solution, the concentration appeared to attain to a constant value. However, in the case of A, it slowly decreased. On the other hand, BH and D showed a peak or plateau in concentration change. Using XRD, it was clarified that $\mathrm{A}, \mathrm{BH}$, and $\mathrm{D}$ crystals transform into $\mathrm{C}$, indicating that $\mathrm{C}$ is the stable form as shown in Fig. 2. The appearance of peaks in concentration changes may indicate that the transformation is by a "solution-mediated mechanism". In solutionmediated transformation, the metastable form dissolves and the stable form nucleates and grows. The 


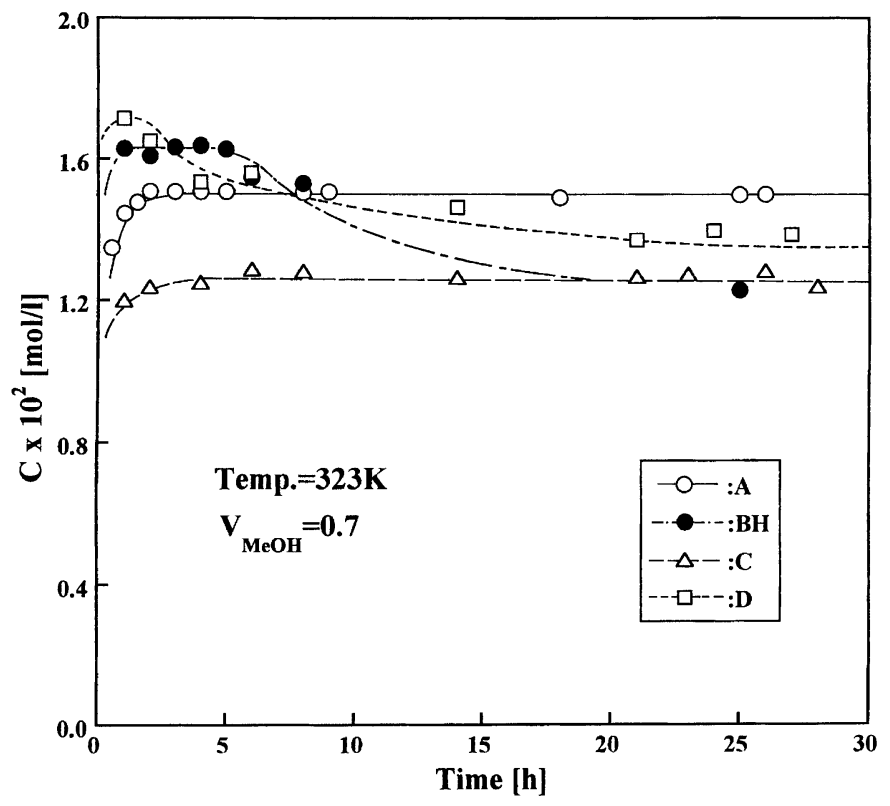

Fig. 1 Typical concentration change of BPT after the excess crystals were added to the solution at $323 \mathrm{~K}$ $\left(V_{\mathrm{MeOH}}=0.7\right)$.

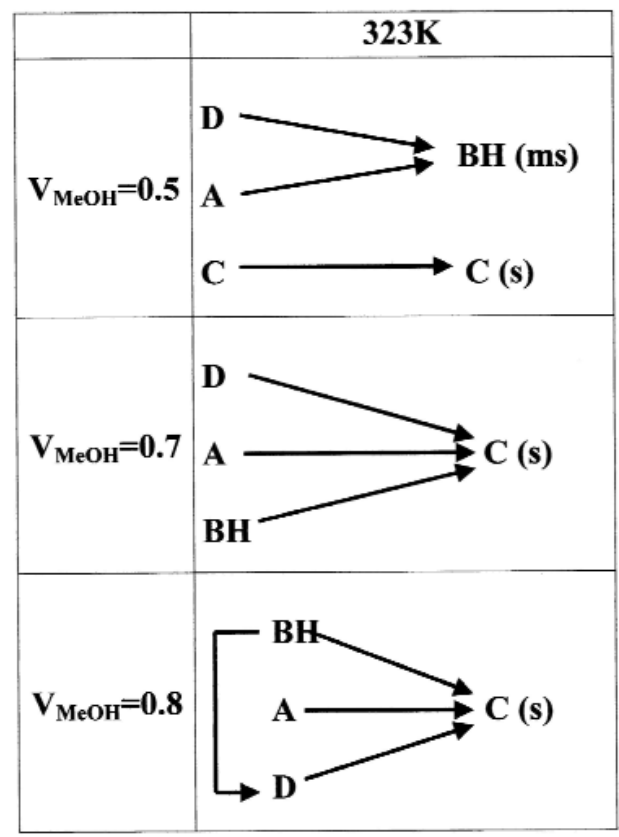

Fig. 2 Transformation behaviors at different solvent compositions (323 K) (ms: metastable form, s: stable form).

solution concentration change during transformation is defined by both of these kinetic processes. Usually the dissolution rate constant is larger than the growth rate constant of crystals. Furthermore, in the early stages of this experiment, only metastable forms were present in solutions. Therefore, the concentration, which increases with the dissolution of the metastable form, tends to approach to the solubility of the metastable form. The dissolution process of the metastable form is believed to be controlled 
by the diffusion of the solute. On the other hand, the growth process of the stable form may include both the diffusion process and the surface reaction process [14]. Practically, it was observed in this system that with fast stirring (using the magnetic stirrer) the dissolution rate of the metastable form was enhanced much more than the crystallization rate (nucleation and growth rate) of the stable form. Therefore, solubility measurements were carried out in this experiment with efficient stirring, using a magnetic stirrer. Under these conditions, the transformation rate at the plateau may be controlled by the growth process of the stable form, and the concentration may be regarded as the solubility of the metastable form [5]. The concentration value at the plateau or peak was observed to be reproducible. Then, the solubilities of $\mathrm{A}$ and $\mathrm{BH}$ crystals were approximated by the concentrations at the plateau or peak.

At a methanol volume fraction $\left(V_{\mathrm{MeOH}}\right)$ of 0.8 , the solubility of $\mathrm{BH}$ became high, and inversely, that of $\mathrm{D}$ decreased in comparison with the solubility at $V_{\mathrm{MeOH}} 0.7$, as shown in Fig. 3. It appeared that the $\mathrm{BH}$ and $\mathrm{D}$ forms transformed into the stable $\mathrm{C}$ form (Fig. 2). This behavior is very similar to that at $\mathrm{V}_{\mathrm{MeOH}}$ 0.7. However, the $\mathrm{BH}$ form sometimes transformed into $\mathrm{C}$ over two steps, i.e., $\mathrm{BH}$ transforms first to D and later to C. It is believed that even for the hydrate (BH) and methanolate (D) crystals, the thermodynamic stability can be correlated with the chemical potential of BPT (X) because BPT is a common component, forming the framework of crystals. The chemical potential difference of BPT $\left[\Delta \mu_{\mathrm{BPT}}(\mathrm{s})\right]$ for the transformation from A to $\mathrm{C}$ and from $\mathrm{D}$ to $\mathrm{C}$ was estimated by eq. 6 to be 360 and

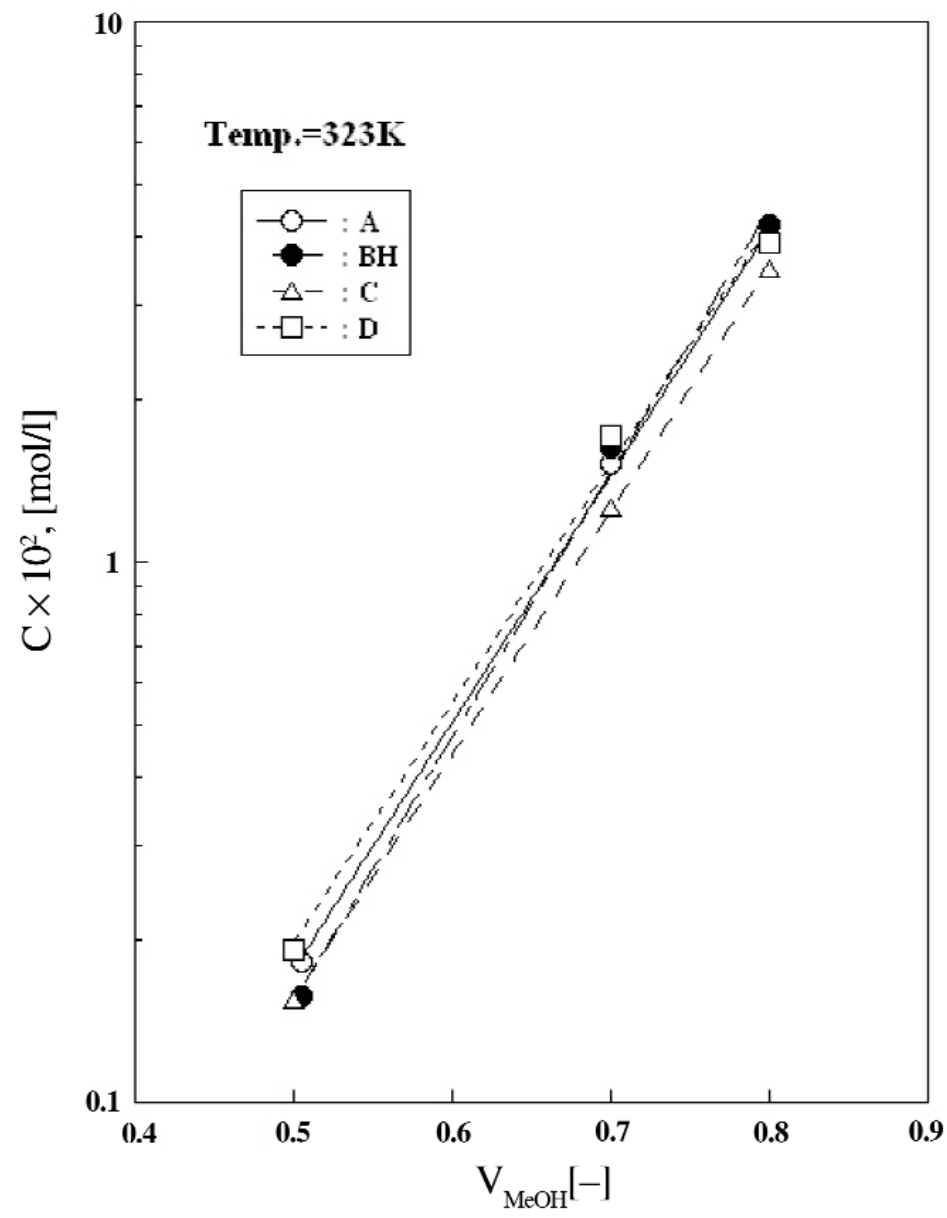

Fig. 3 Dependence of the polymorphic solubility $(\mathrm{C})$ on the methanol volume fraction $\left(V_{\mathrm{MeOH}}\right)$ at $323 \mathrm{~K}$. 
$290 \mathrm{~J} / \mathrm{mol}$. On the other hand, the $\Delta \mu_{\mathrm{BPT}}(\mathrm{s})$ between the $\mathrm{BH}$ and $\mathrm{C}$ forms is as large as $550 \mathrm{~J} / \mathrm{mol}$, i.e., the $\mathrm{BH}$ form is the most unstable. It is expected that the occurrence of the $\mathrm{D}$ form in the transformation from $\mathrm{BH}$ to $\mathrm{C}$ is due to the relatively large free energy difference. Therefore, these results seem to indicate that at relatively large chemical potential differences, nucleation of the metastable form tends to occur, following Ostwald's step rule [15].

When the methanol fraction $\left(V_{\mathrm{MeOH}}\right)$ was decreased from 0.7 to 0.5 , the solubility of BH decreased very much as shown in Fig. 3. In relation to this, both A and D transformed into the BH form (Fig. 2). However, it appears that the $\mathrm{C}$ form is the stable form in these conditions. This indicates that the $\mathrm{A}$ and $\mathrm{D}$ forms transform into another metastable form, $\mathrm{BH}$. The chemical potential differences $\left[\Delta \mu_{\mathrm{BPT}}(\mathrm{s})\right]$ between $\mathrm{D}$ and $\mathrm{BH}(530 \mathrm{~J} / \mathrm{mol})$, and between $\mathrm{A}$ and $\mathrm{BH}(480 \mathrm{~J} / \mathrm{mol})$ are relatively large. On the other hand, the chemical potential difference $\left[\Delta \mu_{\mathrm{BPT}}(\mathrm{s})\right]$ between the $\mathrm{BH}$ and $\mathrm{C}$ forms $(34 \mathrm{~J} / \mathrm{mol})$ is very small. Such a small difference in free energy may also stabilize the metastable $\mathrm{BH}$ form. On account of this, the transformation of BH was not observed during the course of this study. These results may also indicate that the nucleation and growth of the metastable $\mathrm{BH}$ form occurs in preference to that of the most stable form, C. It is believed that the solute-solvent interaction plays an important role in the formation of the cluster or nucleation of each polymorph. At the water-rich content of $V_{\mathrm{MeOH}} 0.5$, nucleation of hydrated BH crystal may be preferable.

When the methanol composition was increased to $V_{\mathrm{MeOH}} 0.95$, every form of $\mathrm{A}, \mathrm{BH}$, and $\mathrm{C}$ became very unstable and transformed into the stable form, D, very quickly. Consequently, the solubility of $\mathrm{A}, \mathrm{BH}$, and $\mathrm{C}$ could not be measured.

From the dependence of the solubility (C) on solvent composition $\left(\mathrm{V}_{\mathrm{MeOH}}\right)$ at $323 \mathrm{~K}$ in Fig. 3, it can be seen that basically the $\mathrm{C}$ form is stable and the A form is metastable all across the methanol composition range. The thermodynamic stability of the $\mathrm{BH}$ and $\mathrm{D}$ forms is intensively influenced by the solution composition. At high methanol compositions, hydrated BH crystals are the most unstable, and at low methanol composition, the most stable form is BH crystal. Inversely, the stability of the D form is increased by increasing the methanol composition. The stability (i.e., solubility) of D is related with the dissociation equilibrium in eq. 7, i.e., with the increase of the methanol composition, the dissociation of the D form is suppressed and the stability of the D form is strongly increased in comparison with A and $\mathrm{C}$, which are not solvated. Inversely, however, the stability of BH crystals relatively decreases due to the progress of the dissociation (eq. 8).

$$
\begin{aligned}
& \mathrm{BPT} \cdot \mathrm{CH}_{3} \mathrm{OH}(\mathrm{D}) \mathrm{BPT}+\mathrm{CH}_{3} \mathrm{OH} \\
& \mathrm{BPT} \cdot \mathrm{H}_{2} \mathrm{O}(\mathrm{BH}) \mathrm{BPT}+\mathrm{H}_{2} \mathrm{O}
\end{aligned}
$$

The equilibrium constant, $K$, in eqs. 9 and 10 can be written as follows,

$$
\begin{aligned}
& K_{\mathrm{H}_{2} \mathrm{O}}=\frac{[\mathrm{BPT}]\left[\mathrm{H}_{2} \mathrm{O}\right]}{\left[\mathrm{BPT} \cdot \mathrm{H}_{2} \mathrm{O}(\mathrm{s})\right]} \\
& K_{\mathrm{CH}_{3} \mathrm{OH}}=\frac{[\mathrm{BPT}]\left[\mathrm{CH}_{3} \mathrm{OH}\right]}{\left[\mathrm{BPT} \cdot \mathrm{CH}_{3} \mathrm{OH}(\mathrm{s})\right]}
\end{aligned}
$$

\section{Effects of temperature on solubility and transformation of polymorphs}

The dependence of the solubility on temperature at $V_{\mathrm{MeOH}} 0.7$ was plotted, as shown in Fig. 4 . It can be seen that the $\mathrm{A}$ and $\mathrm{BH}$ forms are metastable, and the $\mathrm{C}$ form is stable all across the temperature range. However, the stability of the $\mathrm{D}$ form changes dynamically with temperature; It is the most stable at $303 \mathrm{~K}$, whereas it becomes the most unstable at $323 \mathrm{~K}$. It also appears that at high temperatures $\mathrm{A}$ is relatively stable, and at low temperatures $\mathrm{BH}$ becomes more stable than A. The thermodynamic stability of the solvated crystals of BH and D seems to decrease with temperature. It is believed that the dis- 


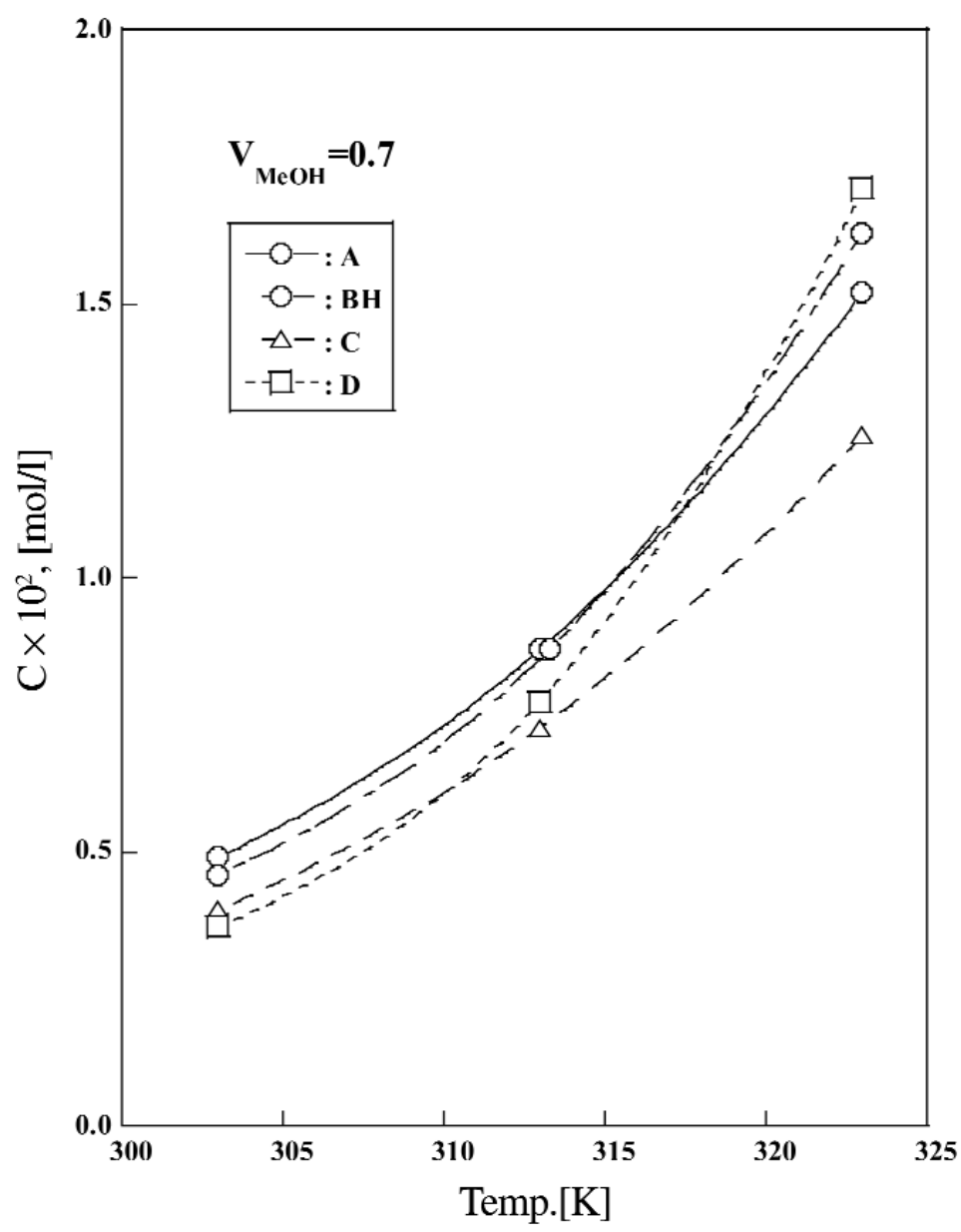

Fig. 4 Dependence of the solubility on temperature at $V_{\mathrm{MeOH}} 0.7$.

sociation of both $\mathrm{BH}$ and $\mathrm{D}$ crystals is accelerated with the increase of temperature, i.e., the $\mathrm{K}$ value in eqs. 9 and 10 increases with temperature.

The temperature dependence of the equilibrium constant, $K$, can be written as eq. 11 ,

$$
\frac{d \ln K}{d(1 / T)}=\frac{-\Delta H^{\circ}}{R}
$$

where $R$ is the gas constant and $\Delta H^{\circ}$ is the standard heat of solution in eqs. 9 and 10 .

The increase of solubility corresponds to the increase of $K$ value, and the increase of $K$ value with temperature means that the standard heat, $\Delta H^{\circ}$, is positive, i.e., endothermic.

At $313 \mathrm{~K}, \mathrm{~A}, \mathrm{BH}$, and D crystals transformed into C crystals at $V_{\mathrm{MeOH}} 0.7$ (Fig. 5). These transformation behaviors are similar to that at $323 \mathrm{~K}$ (Fig. 2). However, during the transformation from $\mathrm{BH}$ to $\mathrm{C}$, transformation to $\mathrm{D}$ was also observed. This may be due to the large chemical potential difference between $\mathrm{BH}$ and $\mathrm{C}(480 \mathrm{~J} / \mathrm{mol})$. The $\Delta \mu_{\mathrm{BPT}}(\mathrm{s})$ value between $\mathrm{BH}$ and $\mathrm{D}$ was estimated to be $310 \mathrm{~J} / \mathrm{mol}$. A similar transformation from $\mathrm{BH}$ to $\mathrm{D}$ was also observed at $323 \mathrm{~K}$ at $V_{\mathrm{MeOH}} 0.8$. This may indicate that the transformation between hydrated crystals, $\mathrm{BH}$, and solvated D crystals is very easy because of the similar configurations of the carboxylic acid group, which were observed with Fourier transform infrared (FTIR) [12]. At $303 \mathrm{~K}$, both A and BH crystals transformed into D crystals at $V_{\mathrm{MeOH}} 0.7$ (Fig. 5). 


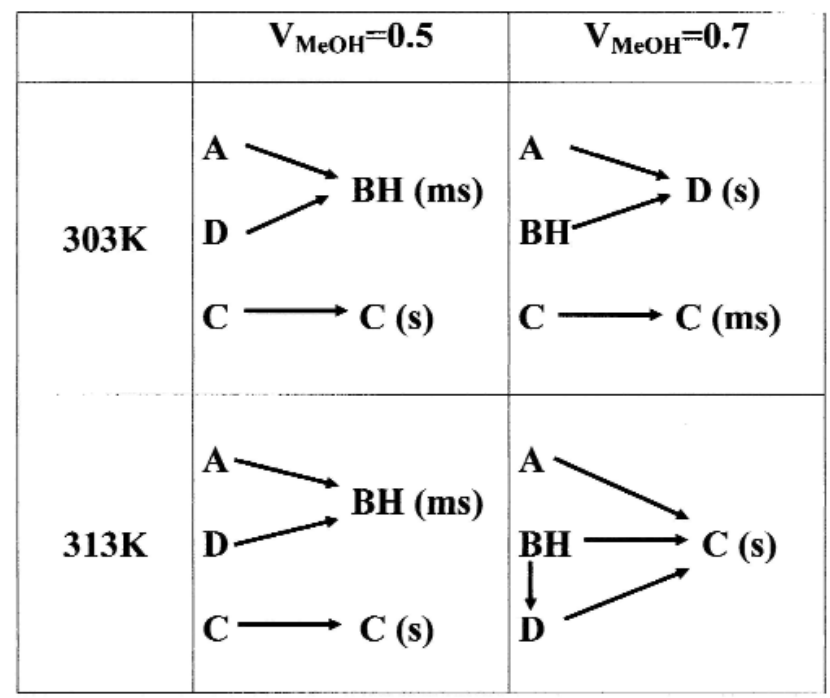

Fig. 5 Transformation behaviors at 303 and $313 \mathrm{~K}\left(V_{\mathrm{MeOH}}=0.5\right.$ and 0.7$)$ (ms: metastable form, s: stable form).

From the solubility measurements, $\mathrm{D}$ is considered to be the stable form at $303 \mathrm{~K}$. Comparing the results at 313 and $323 \mathrm{~K}$, the stability of the $\mathrm{D}$ form increased with decreasing temperature. This also indicates that the dissociation of the methanolated crystals proceeds with increasing temperature. On the other hand, no transformation from the $\mathrm{C}$ to the $\mathrm{D}$ form was observed during the course of this study. This may be due to the relatively small difference of chemical potential difference between the $\mathrm{C}$ and D forms.

The effects of temperature on the solubility and the transformation behaviors of polymorphous crystals at $V_{\mathrm{MeOH}} 0.5$ was also examined. The solubility curve at $V_{\mathrm{MeOH}} 0.5$ is shown in Fig. 6 . The stability of the $\mathrm{D}$ form decreases with increasing temperature, and at $323 \mathrm{~K}$, the $\mathrm{D}$ form is the most unstable, as shown in Fig. 5. However, it can be seen that the influence of temperature on the relative solubility of polymorphs at this solvent composition is smaller than that at $V_{\mathrm{MeOH}} 0.7$. The similarity of the polymorphs' relative thermodynamic stability at each temperature induces similar transformation behaviors across the temperatures range (303-323 K).

The results shown in Figs. 4 and 6 indicate that the solubility of BPT of the solvated crystals (D and $\mathrm{BH}$ ) is much more influenced by the solvent compositions than the true polymorphs (A and C). The solubility ratio of the solvated crystals (eqs. 4 and 5) depend on the solvent composition, whereas the solubility ratio of the true polymorphs are considered to be independent of the solvents. 


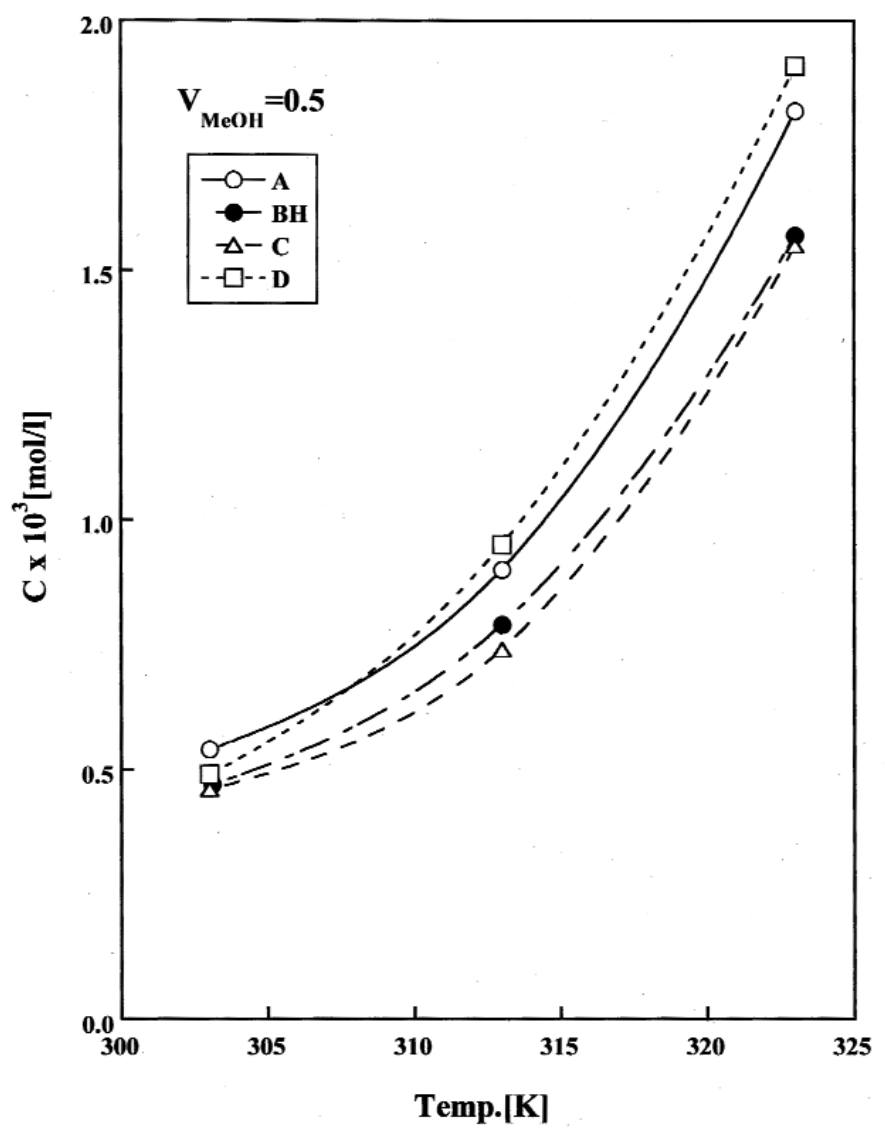

Fig. 6 Dependence of the solubility on temperature at $V_{\mathrm{MeOH}} 0.5$.

\section{Transformation after the crystallization at $323 \mathrm{~K}$}

Crystallization was carried out by adding water as an antisolvent at $323 \mathrm{~K}$. It appears that the crystallized species of polymorphs are the BH and D forms, with only a few exceptions (A form). Both the $\mathrm{BH}$ and $\mathrm{D}$ forms are metastable forms, and their stabilities may be very close to each other, as shown in Fig. 5.

However, it was found that with the increase of the water addition rate, the $\mathrm{BH}$ form tends to crystallize and the portion of $\mathrm{BH}$ in the crystallized solids decreases with the increase of the initial concentration. It was observed that the crystallized $\mathrm{BH}$ form transformed into the A form after the end of water addition. It was also found that at $0.040 \mathrm{~mol} / \mathrm{l}$, only the pure $\mathrm{BH}$ form is obtained at any water addition rate, however, the transformation rate of $\mathrm{BH}$ into the $\mathrm{A}$ form is influenced by the water addition rate. In Fig. 7, the relationship between the molar fraction of the A form $\left(\mathrm{X}_{\mathrm{A} / \mathrm{BH}}\right)$ in crystals and time after the beginning of crystallization at $0.040 \mathrm{~mol} / \mathrm{l}$ is shown. At a high addition rate $(1.42 \mathrm{ml} / \mathrm{min})$, no transformation was observed for $\mathrm{BH}$, at least within $300 \mathrm{~min}$. However, at low addition rates $(0.71$ and $0.28 \mathrm{ml} / \mathrm{min}$ ), the fraction of the A form increased with time. Especially at $0.28 \mathrm{ml} / \mathrm{min}$ after $300 \mathrm{~min}$, an almost pure A form was obtained. Such behavior is very strange, if only the pure BH form crystallizes at the end point of water addition, and the nucleation of the A form seems to be accelerated by the water addition rate. Therefore, we suspect that the slight amount of the A form may be included in BH crystals, which cannot be detected by XRD measurement. The amount of the A form may increase with the decrease of the water addition rate. The A form included in BH crystals may act as seed crystals and 


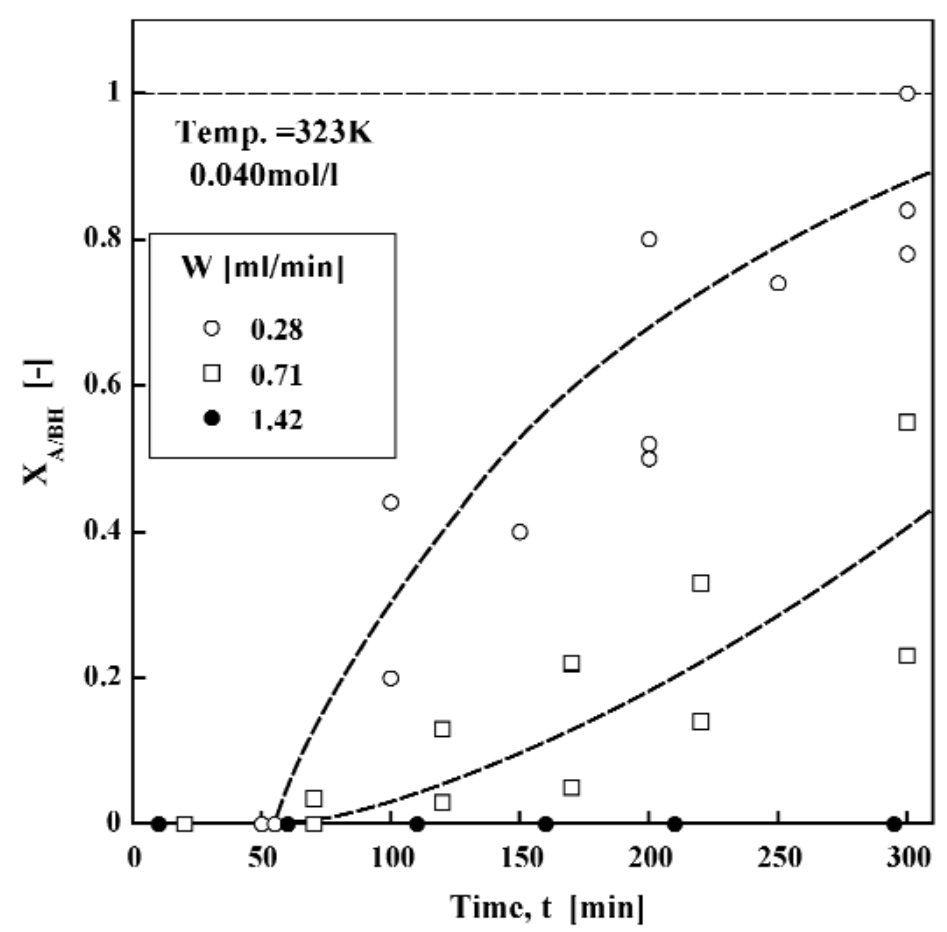

Fig. 7 Influence of the water addition rate $(W)$ on the transformation rate from the $\mathrm{BH}$ to the $\mathrm{A}$ form $\left(C_{0}=0.040 \mathrm{~mol} / \mathrm{l}\right)$.

accelerate the transformation, i.e., the transformation rate decreases with the water addition rate. These results indicate that transformation behavior possibly depends on operational conditions.

\section{CONCLUSIONS}

1. The solubility and transformation behaviors of polymorphs depend remarkably on the solvent's methanol composition and temperature. The thermodynamic stability of solvated crystals is related to the dissociation of the crystals. Transformation behavior was explained by the chemical potential difference between the stable and metastable forms, and the contribution of the preferable nucleation and growth of the stable form due to the specific solute-solvent interaction was emphasized. The solubility of BPT of the solvated crystals (D and BH) is much more influenced by the solvent compositions than the true polymorphs (A and C), and their solubility ratio (eqs. 4 and 5) depend on the solvent composition, whereas the solubility ratio of the true polymorphs are considered to be independent of the solvents.

2. Antisolvent crystallization was carried out by adding water to methanol solutions. The influence of the initial concentration of the solution and the water addition rate on the crystallization behavior of polymorphs was clarified. It was found that the transformation rate after crystallization depends on the initial concentration of BPT and the antisolvent addition rate. The cause of these phenomena was presumed to be a slight inclusion of the stable form in the metastable form. 


\section{REFERENCES}

1. M. Kitamura. J. Cryst. Growth 237-239, 2205-2214 (2002).

2. S. Miyazaki, S. T. Arita, R. Hori, K. Ito. Chem. Pharm. Bull. 22, 638-642 (1974).

3. J. M. Rollinger, E. M. Gstrein, A. Burger. Eur. J. Pharm. Biopharm. 53, 75-86 (2002).

4. D. Murphy, F. Rodriguez-Cintron, B. Langevin, R. C. Kelly, N. Rodriguz-Hornedo. Int. J. Pharm. 246, 121-134 (2002).

5. M. Kitamura. J. Cryst. Growth 96, 541-546 (1989)

6. M. Kitamura. J. Chem. Eng. Jpn. 26, 303-307 (1993).

7. A. R. Brian, M. A. Moustafa, S. A. Khalil, M. M. Motawi. J. Pharm. Pharmacol. 25, 13-20 (1973).

8. M. Kitamura and T. Ishizu. J. Cryst. Growth 192, 225-235 (1998).

9. T. Threlfall. Org. Process Res. Dev. 4, 384-390 (2000).

10. M. L. P. Leitao, J. Canotilho, S. C. R. Ferreira, A. T. Sousa, J. S. Redinha. Thermochim. Acta 411, 53-60 (2004).

11. M. Kitamura and H. Furukawa. J. Cryst. Growth 141, 193-199 (1994).

12. M. Kitamura and K. Nakamura. J. Cryst. Growth 236, 676-686 (2002).

13. R. Haase and H. Schonert. Solid-Liquid Equilibrium, Pergamon Press, Oxford (1969).

14. M. Kitamura and T. Ishizu. J. Cryst. Growth 209, 138-145 (2000).

15. W. Ostwald. Z. Phys. Chem. 22, 289-295 (1897). 